\title{
APLICAÇÃO DE BENTONITA EM UM REGOSSOLO EUTRÓFICO II. EFEITOS SOBRE AS PROPRIEDADES QUÍMICAS DO SOLO ${ }^{1}$
}

\author{
Gilvanise Alves Tito ${ }^{2}$, Lúcia Helena Garófalo Chaves ${ }^{3}$, Hugo Orlando Carvallo ${ }^{3}$ \\ e Norma César Azevedo ${ }^{4}$
}

\begin{abstract}
RESUMO
O presente trabalho foi desenvolvido no período de 1995 a 1996, no Laboratório de Irrigação e Salinidade do Departamento de Engenharia Agrícola/CCT/UFPB. Os efeitos da bentonita Primavera, do município de Boa Vista, PB, sobre as propriedades químicas do solo, foram avaliados em amostras de regossolo eutrólico. As amostras de solo, após coletadas a profundidade de $0-20 \mathrm{~cm}$, foram incubadas por 120 dias com doses da bentonita equivalentes a 0, 30,60 e $90 \mathrm{t} \mathrm{ha}^{-1}$. Após este período, foram feilas avaliações químicas nas amostras de terra. Os tratamentos não influenciaram nos teores de $\mathrm{K}$ e Al trocáveis e $\mathrm{P}$ assimilável, porém houve aumento nos valores de $\mathrm{pH}$ e nos teores de $\mathrm{Ca}, \mathrm{Mg}$ e $\mathrm{Na}$ trocáveis e capacidade de troca catiônica. Os resultados demonstraram que o uso da bentonita Primavera aumentou os valores de $\mathrm{pH}$ correspondentes ao ponto de carga zero do solo.
\end{abstract}

Palavras-chave: bentonita, regossolo eutrófico, propriedades químicas

\section{APPLICATION OF BENTONITE IN A EUTROPHIC RHEGOSOL II. EFFECTS ON THE SOIL CHEMICAL PROPERTIES}

\begin{abstract}
This study was carried out from 1995 to 1996 at the the Laboratory of Irrigation and Salinity of the Department of Agricultural Engineering of the CCT/UFPB. The effects of the Primavera bentonite, from Boa Vista municipality, Paraíba state on the soil chemical properties, were evaluated in samples of a eutrophic rhegosol. Such soil samples of $0-20 \mathrm{~cm}$ depth were incubated for 120 days with doses of bentonite equivalent to $0,30,60$ and $90 \mathrm{tha}^{-1}$. After that, the chemical alterations were evaluated in the samples of the soil. The bentonite did not influence the levels of the exchangeable $\mathrm{K}$ and $\mathrm{Al}$ and available $\mathrm{P}$, but increased soil $\mathrm{pH}$ and exchangeable $\mathrm{Ca}, \mathrm{Mg}$, $\mathrm{Na}$ and $\mathrm{CEC}$. The results showed that the use of the bentonite Primavera increased the $\mathrm{pH}$ corresponding to the soil's ZPC.
\end{abstract}

Key words: bentonite, eutrophic rhegosol, chemical properties

\section{INTRODUÇÃO}

O regossolo eutrólico é um solo arenoso e de baixa capacidade de adsorção de nutrientes. Sua alta permeabilidade acarreta maiores perdas de nutrientes quando comparado a solos argilosos. Apesar dessas limitações, na microrregião de Esperança, no Estado da Paraíba, esse solo é intensamente utilizado na agricultura recebendo, anualmente, grandes quantidades de matéria orgânica.
A bentonita é um argilo-mineral composto predominantemente de esmectita, com alta capacidade de troca catiônica, policatiônica, constituída de magnésio, cálcio, sódio e hidroxônio, sendo que o magnésio e o cálcio contribuem com 50 a $80 \%$ da capacidade total de troca de cátions dessa argila. É encontrada em grande quantidade em depósitos no município de Boa Vista, PB, e aquela que não apresenta as características necessárias para ser utilizada na indústria, é denominada regionalmente "bofe" e tem sido rejeitada e acumulada em

\footnotetext{
1 Parte da Dissertação de Mestrado do primeiro autor apresentada no Centro de Ciências e Tecnologia da Universidade Federal da Paraíba. Campina Grande, PB.

2 Engenheiro Agrícola . Rua Antonio Catão 560). Campina Grande, PB

3 Professores Titulares do Departamento de Engenharia Agrícola do Centro de Ciências e Tecnologia da Universidade Federal da Paraíba. Campina Grande, PB.

${ }^{4}$ Professor Adjunto do Depto. de Engenharia Agrícola do Centro de Ciências e Tecnologia da Universidade Federal da Paraíba. Campina Grande, PB.
} 
grandes montanhas a céu aberto na região, causando problema ambiental.

Da mesma forma que se tem pesquisado a utilização na agricultura de vários resíduos urbanos e industriais (Messias \& Morais, 1992; Logan \& Prezotto, 1992; Ros et al., 1993; Fortes \& Campos Neto, 1995; Novelino et al., 1995; Souza et al., 1996) este trabalho foi desenvolvido com o objetivo de se estudar os efeitos da incorporação de material de bentonita, considerada "bofe", sobre as propriedades químicas de um regossolo eutrólico.

\section{MATERIAL E MÉTODOS}

Este trabalho foi desenvolvido em casa de vegetação pertencente ao Laboratório de Irrigação e Salinidade do Departamento de Engenharia Agrícola do Centro de Ciências e Tecnologia da Universidade Federal da Paraíba, em Campina Grande, PB, no período de 1995 a 1996.

Foi utilizada uma amostra de solo coletada a profundidade de $0-20 \mathrm{~cm}$, de um regossolo eutrófico da microrregião de Esperança do Estado da Paraíba, classificado como areia franca, e uma outra de bentonita, coletada na jazida Primavera, no município de Boa Vista, PB. Esses materiais foram secados ao ar, passados em peneira de $2 \mathrm{~mm}$ de abertura de malha e, em seguida, caracterizados quimicamente segundo metodologias recomendadas por EMBRAPA (1979) (Tabela 1). Os quantitativos utilizados de bentonita corresponderam às doses de $0,30,60$ e $90 \mathrm{tha}^{-1}$.

Tabela 1. Características químicas do regossolo e da bentonita Primavera

\begin{tabular}{|c|c|c|c|c|c|c|c|c|c|c|c|}
\hline Material & $\mathrm{Ca}^{3+}$ & $\mathrm{Mg}^{3+}$ & $\mathrm{Na}^{+}$ & $\mathrm{K}^{+}$ & $\mathrm{H}^{+}$ & $\mathrm{Al}^{3+}$ & CTC & $\mathrm{P}$ & M.O & $\begin{array}{c}\mathrm{pH} \mathrm{H}_{2} \mathrm{O} \\
(1: 2,5)\end{array}$ & CF. \\
\hline & $-\cdots$ & $\cdots$ & $--\mathrm{cl}$ & $\mathrm{I}_{\mathrm{c}} \mathrm{K}$ & & $\cdots$ & 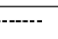 & $\mathrm{mg} \mathrm{dm}^{-3}$ & $\mathrm{~g} \mathrm{~kg}^{-1}$ & & $\mathrm{dS} \mathrm{m} \mathrm{m}^{-1}$ \\
\hline Regossolo & 1,08 & 0,74 & 0,06 & 0,17 & 0,22 & 0,10 & 2,37 & 13,9 & 3,9 & 4,63 & 0,19 \\
\hline Primavera & 20,20 & 28.43 & 5,89 & 0,09 & 0,10 & 0,10 & 54,81 & 12.7 & 0.46 & 7,50 & 1.98 \\
\hline
\end{tabular}

Cada unidade experimental, constituída de $2 \mathrm{~kg}$ de terra, contida em vasos plásticos, misturada e homogeneizada com uma dose de bentonita, foi submetida a um período de incubação de 120 dias, ao longo do qual a umidade foi mantida a $80 \%$ da capacidade de campo. Transcorrido esse período e após a determinação de condutividade hidráulica (ver trabalho anterior) foi retirada uma amostra de cada unidade experimenta, para a determinação das características químicas, segundo metodologias recomendadas por EMBRAPA (1979). Com base nos resultados de argila dispersa em água, determinou-se o grau de floculação das amostras de terra. O ponto de carga zero (PCZ) foi estimado segundo Keng, citado por Uehara (1979) de acordo com a expressão:

$\mathrm{PCZ}=2 \mathrm{pH} \mathrm{KCl}-\mathrm{pH} \mathrm{H}_{2} \mathrm{O}$, em que $\mathrm{pH} \mathrm{KCl}=\mathrm{pH}$ determinado em $\mathrm{KCl} 1 \mathrm{~mol} \mathrm{~L}^{1} \mathrm{e}$

$\mathrm{pH} \mathrm{H}_{2} \mathrm{O}=\mathrm{pH}$ determinado em água destilada.

\section{RESULTADOS E DISCUSSÃO}

Analisando-se os dados da Tabela 2, constata-se que houve tendência dos teores de fósforo assimilável aumentarem enquanto os de potássio trocável diminuíram em função dos tratamentos porém, pela comparação entre as médias, a variação desses teores não foi significativa.

Os valores de $\mathrm{pH}$ em água aumentaram, em geral, em função dos tratamentos (Figura 1); isto ocorreu porque a bentonita tem, originalmente, um pH mais elevado que o solo. Essa mesma tendência foi observada com os valores de $\mathrm{pH}$ em $\mathrm{KCl} 1 \mathrm{~mol} \mathrm{~L}^{-1}$.

Tabela 2. Teores de P assimilável e K trocável das amostras de solo após mistura com bentonita e incubaçẫo durante 120 dias

\begin{tabular}{ccc}
\hline $\begin{array}{c}\text { Doses de Bentonita } \\
\mathrm{l} \mathrm{ha}^{-1}\end{array}$ & $\begin{array}{c}\mathrm{P} \\
\mathrm{mg} \mathrm{dm}^{-3}\end{array}$ & $\begin{array}{c}\mathrm{K} \\
\mathrm{cmol}_{\mathrm{c} \mathrm{kg}}{ }^{-1}\end{array}$ \\
\hline 0 & $13,93 \mathrm{~b}$ & $0,16 \mathrm{a}$ \\
30 & $15,99 \mathrm{ab}$ & $0,17 \mathrm{a}$ \\
60 & $16,33 \mathrm{a}$ & $0,15 \mathrm{a}$ \\
90 & $15,01 \mathrm{ab}$ & $0,15 \mathrm{a}$ \\
\hline
\end{tabular}

Médias seguidas da mesma letra nas colunas não diferem estatisticamente entre si pelo teste de Tukey, a $5 \%$ de probabilidade.

Em geral, estreitas correlações entre o pH em água e em $\mathrm{KCl}$ e as doses da bentonita foram observadas nas amostras de terra do regossolo, obedecendo a equações quadráticas (Figura 1); assim, 99,7 e 99,9\% da variação do $\mathrm{pH}$ em água e em $\mathrm{KCl}$, respectivamente, foram explicados pelas doses da bentonita Primavera, observando-se elevado acréscimo com a primeira dose e tendência de menores incrementos com as doses maiores.

Os valores absolutos do $\mathrm{DpH}$, que correspondem à diferença entre os valores de $\mathrm{pH}$ em $\mathrm{KCl}$ e água, foram crescentes em função dos tratamentos (Tabela 3) demonstrando com isto, aumento na carga líquida negativa dos colóides das unidades experimentais e, consequentemente, na capacidade dessas adsorverem cátions.

$\mathrm{O}$ aumento dos valores de $\mathrm{pH}$, determinado tanto em água quanto em $\mathrm{KCl}$, em função dos tratamentos, fez com que os valores de PCZ aumentassem; entretanto, todos os valores
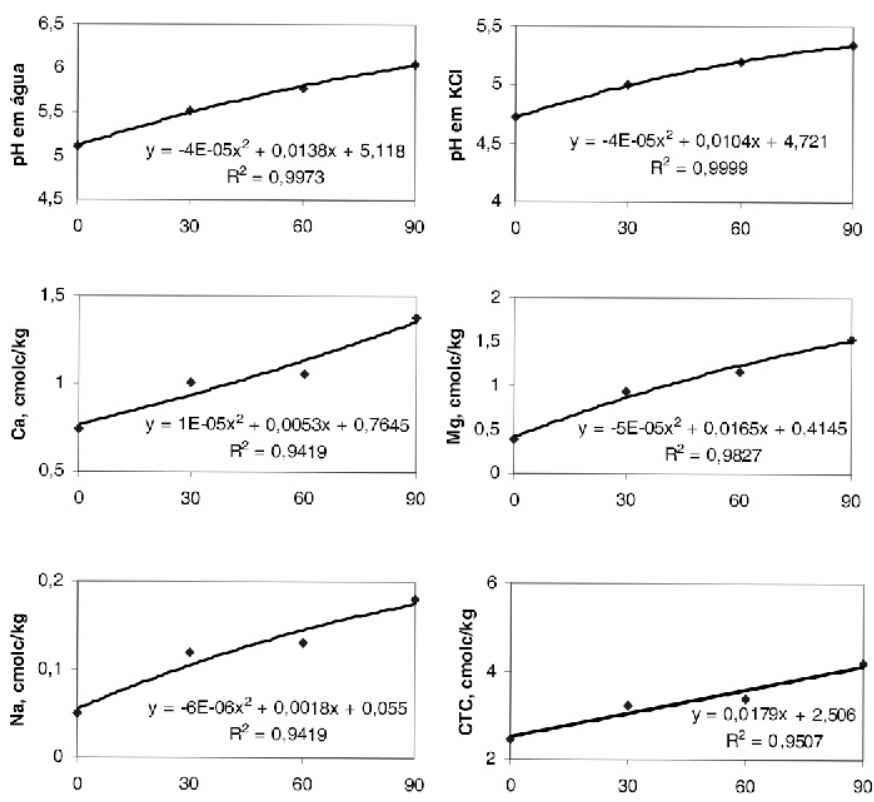

Doses de Bentonita, $\mathbf{t ~ h a}^{-1}$

Figura 1. Eleito das doses crescente da bentonita Primavera nos valores de $\mathrm{pH}$ em água e em KCl, e nos teores de cálcio, magnésio, sódio e capacidade de troca catiônica (CTC) de um regossolo, após incubação duranle 120 dias. 
estimados de PCZ foram menores que os de $\mathrm{pH}$ em água, confirmando, com isto, a predominância de cargas negativas nas amostras de terra (Tabela 3 ).

Tabela 3. Efeito de diferentes doses de bentonita no DpH, PCZ, afastamento e grau de floculação

\begin{tabular}{ccccc}
\hline $\begin{array}{c}\text { Doses } \\
\mathrm{tha}{ }^{1}\end{array}$ & $-\Delta \mathrm{pll}$ & $\mathrm{I}^{\mathrm{C}} \mathrm{C}$ & Nfastamento & $\begin{array}{c}\text { Grau de floculação } \\
\%\end{array}$ \\
\hline 0 & $0,38 \mathrm{~d}$ & $4,34 \mathrm{~b}$ & $0,77 \mathrm{~d}$ & $77,99 \mathrm{c}$ \\
30 & $0,51 \mathrm{c}$ & $4,49 \mathrm{ab}$ & $1,03 \mathrm{c}$ & $84,51 \mathrm{a}$ \\
60 & $0,58 \mathrm{~b}$ & $4,62 \mathrm{a}$ & $1,15 \mathrm{~b}$ & $83,55 \mathrm{ab}$ \\
90 & $0,71 \mathrm{a}$ & $4,64 \mathrm{a}$ & $1,41 \mathrm{a}$ & $82,34 \mathrm{~b}$ \\
\hline
\end{tabular}

Médias seguidas da mesma letra nas colunas, não diferem estatisticamente entre si pelo teste de Tukey a $5 \%$ de probabilidade.

$\mathrm{O}$ afastamento entre os valores de $\mathrm{pH}$ em água e aqueles correspondentes ao PCZ, aumentou em função dos tratamentos, indicando ter ocorrido aumento na carga líquida negativa com a aplicação da bentonita (Tabela 3) o que favoreceu o aumento da capacidade de troca cationica das amostras de terra (Figura 1). Segundo Uehara (1979) e Netto et al. (1995) quanto maior o afastamento, maior a carga líquida negativa dos colóides, o que provoca maior repulsão eletrostática, diminuindo a floculação; no entanto, a incorporação da bentonita provocou aumento no grau de floculação em relação à testemunha, apesar de não ter havido diferença entre as doses aplicadas (Tabela 3). Este aumento do grau de floculação ocorreu, provavelmente, devido à diminuição da espessura da dupla camada difusa provocada pela elevação dos teores de cátions trocáveis, divalentes, predominantes na bentonita.

A incorporação das doses crescentes da bentonila nas amostras de terra provocou aumento nos teores de cálcio trocável, explicando $94,19 \%$ da variação do referido cátion, segundo equações de regressão quadráticas (Figura 1); porém, devido à provável perda de cátions durante a lixiviação, apenas as amostras de terra que receberam $90 \mathrm{t} \mathrm{ha}^{-1}$ de bentonita apresentaram, após a incubação, teores de cálcio acima daquele apresentado pelo regossolo (Tabela 1). Da mesma forma que o cálcio, 98,3\% da variação dos teores de magnésio foram explicados pelas doses crescentes da bentonila, obedecendo a equações de regressão quadráticas. As amostras de terra que receberam bentonita apresentaram teores de magnésio maiores que o regossolo (Tabela 1). Os teores mais elevados de magnésio são devidos ao fato da bentonita apresentar, originalmente, altos teores desse elemento.

Em razão da bentonita apresentar sódio na composição química, a sua incorporação no regossolo aparentemente deveria ser preocupante, pois poderia torná-lo sódico, como foi observado por Chaves et al. (1993) quando trabalharam com sistemas fechados; no entanto, como as unidades experimentais passaram por um processo de lixiviação e por serem os elementos químicos cálcio e magnésio adsorvidos prefencialmente em relação ao sódio, devido a maior seletividade dos mesmos, impedindo o acúmulo de sódio trocável, apesar dos teores de sódio no solo terem aumentado em função dos tratamentos, a sodificação, neste caso, não foi observada.

Os valores da capacidade de troca catiônica das amostras de terra variaram de forma semelhante aos teores de cálcio e magnésio, isto é, aumentaram em função das doses de bentonita. Apesar da lixiviação, a capacidade de troca catiônica das amostras de terra, após a incubação, foi maior que a do regossolo, o que demonstra o efeito benéfico da incorporação da bentonita no solo.

\section{CONCLUSÕES}

1.A bentonita Primavera atuou de forma eficiente no aumento do $\mathrm{pH}$ e da capacidade de troca catiônica do regossolo.

2. A bentonila Primavera provocou aumento nos valores de $\mathrm{pH}$ correspondentes ao PCZ do solo.

\section{REFERÊNCIAS BIBLIOGRÁFICAS}

CHAVES, L.H.G. ; AZEVEDO, N.C. \& TITO, G.A. Efeito da aplicação da bentonita nas propriedades químicas de um regossolo distrófico. In: CONGRESSO BRASILEIRO de CIÊNCIA de SOLO, 24., 1993, Goiânia, Resumos. Goiânia, Sociedades Brasileira de Ciência do Solo, 1993. p. $277-278$.

EMBRAPA. Serviço Nacional de Levantamento e Conservação do Solo. Manual e mélodos de análise de conservação de solo. Rio de Janeiro, EMBRAPA-SNLCS, 1979.

FORTES, J.L.O. \& CAMPOS NETO, D. Alterações nas características químicas do solo e produção vegetal do milho com uso de resíduos de bauxita e cinza de caldeira. In: CONGRESSO BRASILEIRO DE CIÊNCIA DO SOLO, 25., 1995, Viçosa. Resumos. Campinas, Sociedade Brasileira de Ciência do Solo, 1995. p.1331-1333.

LOGAN, T.J. \& PREZOTTO, M.E.M. Avaliação da possibilidade de uso agronômico de lodo de esgoto tratado com resíduo de indústria de cimento (CKD-Sludge). In: REUNIÃO BRASILEIRA DE FERTILIDADE DO SOLO E NUTRIÇÃO DE PLANTAS, 20., Piracicaba, 1992. Anais. Campinas, Sociedade Brasileira de Ciência do Solo, 1992. p.386-387.

MESSIAS, A.S. \& MORAIS, F.A. Emprego do lixo urbano na adubação do milheto. In: REUNI ÃO BRASILEIRA DE FERTILIDADE DO SOLO E NUTRIC ÃO DE PLANTAS, 20., Piracicaba. 1992. Anais. Campinas, Sociedade Brasileira de Ciência do Solo, 1992. p.384-385.

NETTO, A.R.; J.M. BRAGA \& L.M.COSTA. Efeito da calagem sobre a dispersão de argilas de solos com diferentes características mineralógicas. In: Congresso Brasileiro de Ciências do Solo, 25., 1995, Viçosa-MG. Resumos. Viçosa, Sociedade brasileira de Ciência do Solo. 1995. p. 301303.

NOVELINO, J.O. ; LEITE, P.C. ; PROENÇA, S.S. \& SILVA, M.L. Características químicas de dois latossolos de Dourados, MS, submetidos à aplicação de pó de basalto. In: CONGRESSO BRASILEIRO DE CIÊNCIA DO SOLO, 25., 1995, Viçosa. Resumos. Campinas, Sociedade brasileira de Ciência do Solo, 1995. p.1334-1335.

ROS, C.O. ; AITA, C. ; CERETTA, C.A. \& FRIES, M.R. Lodo de esgoto: efeito imediato no milheto e residual na sociação aveia-ervilhaca. Rev. bras. Ci. Solo, Campinas, 17:257-261, 1993.

SOUZA, C.M. , FIGUEIREDO, M.S., COSTA, L.M. \& GALVÃO, J.C.C. Uso do lodo primário da indústria de celulose e papel em povoamentos de eucalípto. In: REUNIÃO BRASILEIRA DE FERTILIDADE DO SOLO E NUTRIÇÃO DE PLANTAS, 27., Manaus, 1996. Resumo. Campinas, Sociedade brasileira de Ciência do Solo, 1996. p.537-538.

UEHARA, G. Mineral-chemical properties of oxisols. In: INTERNATIONAL SOIL CLASSIFICATION WORKSHOP, 2., Malaysia, 1978. Bangkok, Soil Survey Division, Land Development Department, 1979. Part I, p. $45-60$. 